\title{
Characterization of Paramagnetic Species in Seeds by Electron Paramagnetic Resonance (EPR)
}

\author{
V. M. Barbana, C. L. B. Guedes and E. Di Mauro \\ Laboratory of Fluorescence and Electron Paramagnetic Resonance (LAFLURPE), \\ CCE, State University of Londrina, Londrina, PR, 86051-990 (Brazil) \\ Phone/Fax number: +55 43 33714684, e-mail: carmen@uel.br, dimauro@uel.br
}

\begin{abstract}
Paramagnetic species were characterized in the seeds of radish wild, rice, mustard, wheat, oats, sorghum, sunflower, soybean, cotton, beans, maize and barley by Electron Paramagnetic Resonance (EPR). Some iron complexes such as goethite, hematite, magnetite, and ferrihydrite, normally present in the soil, were also investigated by EPR, since their signals can, a priori, be present in EPR spectra of seeds. The EPR experiments were performed at X-band microwave frequency $(9.3 \mathrm{GHz})$ on the JEOL spectrometer (JES-PE-3X) from 77 to $385 \mathrm{~K}$ and on the BRUKER spectrometer (Elexsys E-580) in a temperature range from 30 to $70 \mathrm{~K}$. In the EPR spectra of the seeds, it was detected the same complex of $\mathrm{Fe}^{3+}$ found in goethite, with $g=2.0 \pm 0.1$ in all the investigated seeds. In addition, free radicals have also been detected with $\mathrm{g}=2.004 \pm 0.002$, on all seeds, and with $g=2.013$ only in sorghum seeds. The sunflower seeds showed the highest signal intensity of the free radical. During the temperature variation, changes were observed in the spectra, in a manner that at low temperature $(30 \mathrm{~K})$, beyond the higher intensity on signal of the goethite and free radical, the spectra of the seeds also showed signal of hematite and traces of $\mathrm{Mn}^{2+}$.
\end{abstract}

\section{Key words}

Biomass, $\mathrm{Fe}^{3+}$, free radical, goethite, hematite.

\section{Introduction}

Since the 1970's, programs have been developed for renewable fuels in order to replace petroleum. A program that has been exhaustively discussed and encouraged is the biodiesel, which would replace the diesel, a fossil fuel, for biodiesel, a renewable fuel. Biodiesel is a fatty acid ester, renewable and biodegradable, which can be obtained by transesterification, a chemical process that uses animal fat and/or vegetal oils with alcohol in the presence of a catalyst [1]. Plant seed oils such as soybean, maize, and sunflower, among others are used in the production of biodiesel. As seeds are the basis for production of oil and consequently processed into biodiesel, the goal of this project is to characterize and compare paramagnetic species present in the seeds by Electron Paramagnetic Resonance (EPR). In the near future biodiesel can be used in large scale. These paramagnetic species are of great importance, once they may be present in the seed's oils, in all the industrial process of the biodiesel and possibly in the air as pollutants.

Paramagnetic species were characterized in the seeds of wild radish, rice, mustard, wheat, oats, sorghum, sunflower, soybean, cotton, beans, maize and barley by EPR. Some iron complexes such as goethite $(\mathrm{FeOOH})$, hematite $\left(\mathrm{Fe}_{2} \mathrm{O}_{3}\right)$, magnetite $\left(\mathrm{Fe}_{3} \mathrm{O}_{4}\right)$ and ferrihydrite $\left(\mathrm{Fe}_{5} \mathrm{HO}_{8} .4 \mathrm{H}_{2} \mathrm{O}\right)$, normally present in the soil, were also investigated by EPR, since their species can, a priori, be present in appreciable quantities in the soil, and therefore in EPR spectra of seeds.

\section{Experimental}

EPR experiments were performed at the X-band microwave frequency $(9.3 \mathrm{GHz})$ and a magnetic field modulation of $100 \mathrm{kHz}$ on the JEOL (JES-PE-3X) equipment in a temperature range from 77 to $385 \mathrm{~K}$, using variable temperature controller (JES-VT-3A), with a flow of nitrogen, and on the BRUKER spectrometer (Elexsys E-580) in a temperature range from 30 to $70 \mathrm{~K}$. A standard sample of MgO: $\mathrm{Mn}^{2+}(\mathrm{g}=1.981$ of the fourth line) was maintained in the EPR cavity of the JEOL spectrometer, the data were recorded simultaneously with the sample. Samples were introduced into $4 \mathrm{~mm}$ quartz EPR tubes that were previously checked for the absence of any spurious signal. In addition to the factor $g$, the line width peak to peak and the EPR signal intensity were used to determine the relative quantity of paramagnetic species in each sample, measuring the mass of the seeds and normalizing their intensities for $1 \mathrm{~g}$ of sample. Afterwards, it was compared with the signal intensity of the $\mathrm{MgO}: \mathrm{Mn}^{2+}$.

\section{Results and Discussion}

In the EPR spectra of the seeds, we detected the same complex of $\mathrm{Fe}^{3+}$ found in goethite (Fig. 1), with $\mathrm{g} 2$ in all the investigated seeds. In addition, free radicals have also been detected with $g=2.004 \pm 0.002$, on all seeds, and with 
Table 1 - Summary of the EPR parameters of the seeds

\begin{tabular}{|c|c|c|c|c|c|c|}
\hline \multirow{2}{*}{ Seeds } & \multicolumn{3}{|c|}{$\mathrm{Fe}^{3+}$} & \multicolumn{3}{|c|}{ Organic free radical } \\
\hline & $\mathrm{g}$ & $\Delta \mathrm{H}$ (Gauss) & RI & $\mathrm{g}$ & $\Delta \mathrm{H}$ (Gauss) & $\mathrm{RI}^{*}$ \\
\hline Radish wild & $2.1 \pm 0.2$ & $899 \pm 50$ & 7.4 & $2.004 \pm 0.003$ & $10 \pm 2$ & 2.0 \\
\hline Rice & $2.1 \pm 0.2$ & $880 \pm 50$ & 3.5 & $2.004 \pm 0.003$ & $10 \pm 2$ & 2.1 \\
\hline Mustard & $2.1 \pm 0.2$ & $744 \pm 50$ & 3.3 & $2.005 \pm 0.002$ & $10 \pm 1$ & 6.9 \\
\hline Wheat & $2.0 \pm 0.2$ & $789 \pm 50$ & 2.3 & $2.005 \pm 0.003$ & $10 \pm 2$ & 1.0 \\
\hline Oats & $2.0 \pm 0.2$ & $749 \pm 50$ & 2.1 & $2.005 \pm 0.003$ & $10 \pm 2$ & 1.2 \\
\hline Sorghum & $2.1 \pm 0.2$ & $873 \pm 50$ & 1.4 & $2.004 \pm 0.003$ & $10 \pm 2$ & 1.8 \\
\hline Sunflower & $2.0 \pm 0.2$ & $812 \pm 50$ & 1.3 & $2.003 \pm 0.001$ & $7 \pm 1$ & 45.7 \\
\hline Soybean & $2.0 \pm 0.2$ & $778 \pm 50$ & 1.3 & - & - & - \\
\hline Cotton & $2.1 \pm 0.2$ & $804 \pm 50$ & 1.1 & $2.004 \pm 0.003$ & $7 \pm 2$ & 3.3 \\
\hline Beans & $2.1 \pm 0.2$ & $792 \pm 50$ & 1.0 & $2.004 \pm 0.003$ & $10 \pm 2$ & 1.0 \\
\hline Maize & $2.1 \pm 0.2$ & $852 \pm 50$ & 1.0 & $2.003 \pm 0.003$ & $10 \pm 2$ & 1.5 \\
\hline Barley & $2.0 \pm 0.2$ & $826 \pm 50$ & 1.0 & $2.005 \pm 0.003$ & $10 \pm 2$ & 2.0 \\
\hline Goethite & $2.0 \pm 0.2$ & $740 \pm 50$ & - & - & - & - \\
\hline
\end{tabular}

Relative intensity of the EPR signals

$\mathrm{g}=2.013$ only in sorghum seeds at room temperature. The sunflower seeds showed the highest signal intensity of the free radical with $g=2.003 \pm 0.001$ (Table 1). Saab and Martin-Neto [2] attributed to semiquinone, the organic free radical signal with $\mathrm{g}=2.004$ found in soil organic matter. Saifutdinov et al. [3] determined values of the factor $g$ for several free radicals. In the seeds, the organic free radicals with $\mathrm{g}=2.003$ were due to the unpaired electrons interacting with the semiquinone and in the radicals with $\mathrm{g}=2.013$, the interactions were with the peroxides. All the others seeds investigated showed EPR spectra similar to the spectra of Fig 1, differing only in intensities (Table 1).

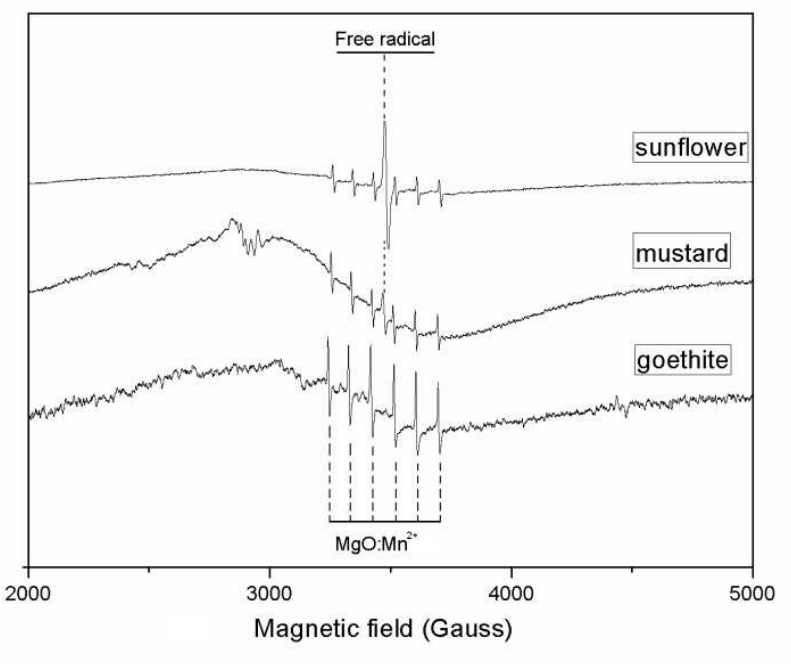

ig. 1. Spectra EPR of seeds and goethite.

Fig. 2 shows the EPR spectra of the mustard seed and goethite at $30 \mathrm{~K}$. The spectrum of the mustard changed and showed an aspect a little different to spectra found for the seeds at room temperature (Fig. 2), i. e., beyond the higher intensity on the signal of the goethite $(\mathrm{g}=2.062$ and $\Delta \mathrm{H}=317)$ and free radical $(\mathrm{g}=2.0044$ and $\Delta \mathrm{H}=10)$, besides that, the spectrum of the mustard also showed hematite, normally present in soil samples [4] with a overlapping line $(g=2.0$ and $\Delta H=526)$ to goethite line $(g=2.062$ and
$\Delta \mathrm{H}=317$ Gauss), and two lines ( $\mathrm{g}=5.8$ and $\mathrm{g}=4.3$ ) on the left of the spectrum (Fig. 2). The spectrum showed also traces of $\mathrm{Mn}^{2+}$, six lines ( $\mathrm{g}=2.022$ and $\mathrm{A}=91$ Gauss) overlapping to goethite line $(g=2.062$ and $\Delta \mathrm{H}=317$ Gauss), that is not the standard $\mathrm{MgO}: \mathrm{Mn}^{2+}$, because in this experiment it did not use the standard. Manganese is usually present in seeds samples [5-10], but it was not detected in our samples in the spectra at room temperature. This could be due to the fact that the $\mathrm{Fe}^{3+}$ showed an intense and wide EPR line which is superposed by the manganese lines [11], since $\mathrm{Mn}^{2+}$ associated with organic matter has interaction that broadens the signal and, consequently, the EPR line disappears [12]. Mcbride [13] verified the loss of the EPR signal of $\mathrm{Mn}^{2+}$ due to the considerable linewidth enlargement caused by very stable bonds of $\mathrm{Mn}^{2+}$ with carboxylic acids. All the others seeds investigated showed EPR spectra at $30 \mathrm{~K}$ similar to the spectrum of the mustard. Thus, these results confirm that the seeds showed structures of $\mathrm{Fe}^{3+}$ similar to goethite, in addition to small quantities of other species (hematite and $\mathrm{Mn}^{2+}$ ).

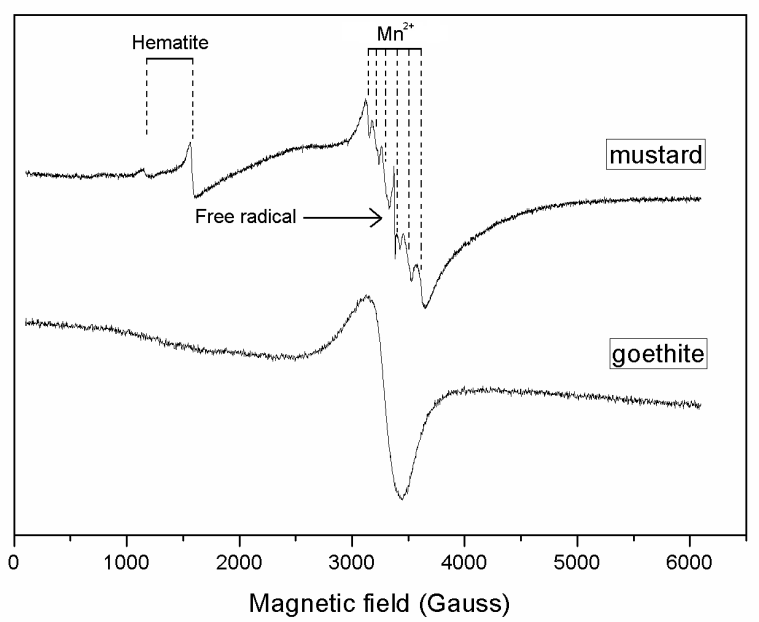

Fig. 2. Spectra of the mustard and goethite at $30 \mathrm{~K}$. 
With the purpose of examining the relationship between the soil type and the EPR signal exhibited by the paramagnetic species in the seeds, the research may continue in the future study with the seeds of plants grown in other soils. It observes the behaviour of the EPR signal, if it is similar or different than signals already studied in the present project.

\section{Conclusion}

According to the EPR spectra, the seeds showed signals of organic free radicals and $\mathrm{Fe}^{3+}$, in addition to traces of $\mathrm{Mn}^{2+}$. The free radical present in the seeds of wild radish, rice, mustard, wheat, oats, sorghum, sunflower, soybean, cotton, beans, maize and barley, with $g=2.003 \pm 0.002$, is due to the unpaired electron interacting with the semiquinone. The sorghum seed showed, beyond this, organic free radical with factor the $\mathrm{g}=2.013$ which is due to the peroxyl radical. The $\mathrm{Fe}^{3+}$ signals exhibited by seeds are due to goethite, but hematite was also detected in small quantities in all the samples.

\section{Acknowledgement}

This project was financed by "Coordenação de Aperfeiçoamento de Pessoal de Nível Superior" (CAPESBrazil), Brazilian financial agency. We also thank MINEROPAR (Minerais do Paraná S.A.) for providing us samples of various rocks and minerals, which were useful for mapping paramagnetic species present in various seed samples, and to the Group of Molecular Biophysics "Sérgio Mascarenhas" IFSC - USP for the EPR spectra at low temperature.

\section{References}

[1] L.C. Meher, D. Vidya Sagar and S.N. Naik, "Technical aspects of biodiesel production by transesterification-a review", Renewable and Sustainable Energy Reviews 2006, Vol. 10, pp. 248-268.

[2] S.C. Saab and L. Martin-Neto, "Characterization by Electron Paramagnetic Resonance of Organic Matter in Whole Soil (Gleysoil) and Organic-Mineral Fractions", Journal of the Brazilian Chemical Society 2008, Vol. 19, n. 3, pp. 413-417.

[3] R.G. Saifutdinov, L.I. Larina, T.I. Vakul'skaya and M.G. Voronkov, Electron paramagnetic resonance in biochemistry and medicine, Kluwer Academic/ Plenum Publishers, New York (2001), p. 268.

[4] R.E. Siqueira, M.M. Andrade, D.F. Valezi, C.E.A. Carneiro, J.P.P. Pinese, A.C.S. Da Costa, D.A.M. Zaia, R. Ralisch, W. M. Pontuschka, C.L.B. Guedes and E. Di Mauro, "EPR, FT-IR and XRD investigation of soils from Paraná, Brazil", Applied Clay Science 2011, Vol. 53, pp. 42-47.

[5] M. Ukai and Y. Shimoyama, "Free radicals in irradiated pepper: An electron spin resonance study", Appl. Magn. Reson. 2003, Vol. 24, pp. 1-11.

[6] R.W.A. Franco, L. Martin-Neto, M.S.A. Kato, G.R. Furlan, J.M.M. Walder and L.A. Colnago, "Identification of Irradiation Treatment in Black Pepper by Electron Paramagnetic Resonance", International Journal of Food Science and Technology 2004, Vol. 39, pp. 395-401.

[7] M. Ukai and Y. Shimoyama, "Free radicals in irradiated wheat flour detected by electron spin resonance", Appl. Magn. Reson. 2005, Vol. 29, pp. 315-324.
[8] H. Nakamura, M. Ukai and Y. Shimoyama, "An electron spin resonance study of gamma-ray irradiated ginseng", Spectrochim. Acta Part A 2006, Vol. 63, pp. 883-887.

[9] M. Ukai, H. Kameya, H. Nakamura and Y. Shimoyama, "An electron spin resonance study of dry vegetables before and after irradiation", Spectrochim. Acta Part A 2008, Vol. 69, pp. 1417-1422.

[10] M. Kikuchi, M.S. Hussain, N. Morishita, M. Ukai, Y. Kobayashi and Y. Shimoyama, "ESR study of free radicals in mango", Spectrochim. Acta Part A 2010, Vol. 75, pp. 310-313.

[11] C.A. Ceretta, C. Bayer, D.P. Dick, L. Martin-Neto and L.A. Colnago, Métodos espectroscópicos, in: G.A. Santos and F.A.O. Camargo (Eds.), Fundamentos da matéria orgânica do solo: ecossistemas tropicais e subtropicais, Gênesis, Porto Alegre (1999), pp. 293-336.

[12] S.G. Moreira, L.I. Prochnow, J.C. Kiehl, L. Martin-Neto and V. Pauletti, "Formas químicas, disponibilidade de manganês e produtividade de soja em solos sob semeadura direta”, Revista Brasileira de Ciência do Solo 2006, Vol. 30. Obtainable from http://www.scielo.br/scielo.php?pid=S0100$06832006000100013 \&$ script=sci_arttext.

[4] M.B. McBride, Surface chemistry of soil minerals, In: J. B. Dixon and S.B. Weed (Eds.), Minerals in soil environments, SSSA Book Series 2nd Edition, Madison (1989), pp. 35-88. 